\title{
Construction and Characterization of an Adenovirus Type 5/Adenovirus Type 12 Recombinant Virus
}

\author{
R. BERNARDS, ${ }^{1}$ M. J. VAESSEN, A. J. VAN DER EB, AND J. S. SUSSENBACH* \\ Department of Medical Biochemistry, Sylvius Labrratories, Wassenaarseweg 72, 2839 AL Leiden, \\ The Netherlands, and *Iaboratory for Physiological Chemistry, Vondellaan 24a, \\ 3521 GG Utrecht, The Netherlands
}

Received April 18, 1983; accepted July 25, 1983

\begin{abstract}
We have constructed an adenovirus type 5 (Ad5) recombinant virus in which the early region $1 b$ (E1b) of the nononcogenic Ad5 is replaced by the E1b region of the highly oncogenic Ad12. Analysis of cells lytically infected with the recombinant virus showed that both the Ad5 E1a genes and the Ad12 E1b genes are faithfully expressed. The recombinant virus replicates efficiently in human embryonic kidney cells and in HeLa cells, indicating that the Ad12 E1b region can fully replace the Ad5 E1b region in lytic infection. Inoculation of the Ad5/Ad12 hybrid virus into newborn hamsters did not result in development of tumors. This shows that the E1b region of Ad12, previously shown to be responsible for the high oncogenic potential of Ad12-transformed cells in nude mice is not capable of converting the nononcogenic Ad5 into an oncogenic virus.
\end{abstract}

\section{INTRODUCTION}

Human adenoviruses vary in their potential to induce tumors in rodents. Some adenovirus serotypes are highly oncogenic (e.g., Ad12), while others are completely nononcogenic (e.g., Ad5) in newborn hamsters (Flint, 1980). It is not known which gene(s) are responsible for this difference in oncogenic potential, mainly because of the lack of well-characterized mutants of the oncogenic serotypes. The genes that are most likely responsible for the difference in oncogenicity among the adenovirus subgroups are those encoded by early region 1 (E1) which is situated at the extreme left end of the viral genome in all serotypes studied so far. This part of the viral genome is responsible for cell transformation in vitro (Graham et al, 1974; Shiroki et al, 1977) and also determines the oncogenic potential of region E1-transformed cells, i.e., rat cells transformed by the nononcogenic subgroup $\mathrm{C}$ adenoviruses are nononcogenic in the syngeneic host (McAllister et al, 1969; Harwood and Gallimore, 1975),

\footnotetext{
${ }^{1}$ Author to whom requests for reprints should be addressed.
}

while rat cells transformed by the highly oncogenic subgroup A adenoviruses are highly oncogenic in rats (Freeman et al, 1967; Harwood and Gallimore, 1975; Shiroki et al., 1977; Mak et al, 1979). Therefore, the difference in oncogenicity of the various adenovirus-transformed cells seems to be determined by functional differences in their early region 1 genes.

The factors which influence the oncogenic potential of the virus might well be more complex than those determining the oncogenicity of adenovirus-transformed cells. For instance, the 19-kDa E3 glycoprotein which is known to be associated with class I proteins of the major histocompatibility complex (Signäs et al, 1982), might be of importance in this respect.

We have recently shown that the difference in oncogenicity between Ad5- and Ad12-transformed cells in nude mice is specified by early region $1 \mathrm{~b}$, one of the two subregions of the transforming region E1 (Bernards et al., 1982; Van den Elsen et al., 1982), and more specifically by the large E1b tumor antigen (Bernards et al., 1983a). To investigate whether the difference in oncogenicity between Ad5 and Ad12 vi- 
ruses in newborn hamsters can also be explained by functional differences in their E1b genes, we have constructed an Ad5 virus in which the $E 1 b$ region is replaced by the Ad12 E1b region. It will be shown that replacement of the $\mathrm{E} 1 \mathrm{~b}$ region of Ad5 by that of Ad12 does not convert the hybrid to an oncogenic virus.

\section{MATERIALS AND METHODS}

\section{Cells and Viruses}

The Ad5 mutant dl 309 was grown on human KB cells. Large scale propagation of the recombinant virus was performed on KB or HeLa cells. KB and HeLa cells were grown in Eagle's minimal essential medium (MEM) supplemented with $8 \%$ newborn calf serum. The 293 cells in MEM plus $10 \%$ fetal calf serum. Infected cells were incubated in MEM plus 2\% horse serum.

\section{Preparation of Ad5 dl 309 XbaI A-Frag- ment-Terminal Protein Complex}

Highly concentrated cesium chloridepurified Ad5 dl 309 virus was lysed by adding an equal volume of $8 \mathrm{M}$ guanidinium$\mathrm{HCl}$ in TE-PMSF (10 mM Tris, $\mathrm{pH} 7.6,1$ $\mathrm{m} M$ EDTA, $10^{-4} M$ phenylmethylsulfonylfluoride). The DNA-protein complex was subsequently loaded on a $5-20 \%$ sucrose gradient in $4 \mathrm{M}$ guanidinium- $\mathrm{HCl}$ and spun for $20 \mathrm{hr}$ at $30,000 \mathrm{rpm}$ in a Beckman SW41 rotor. DNA containing fractions were pooled, BSA was added to $0.5 \mathrm{mg} / \mathrm{ml}$ and dialyzed against $3 \times 1$ liter of TE-PMSF. Dialyzed DNA-protein complex was digested to completion with $\mathrm{XbaI}$ and loaded on a second sucrose gradient as described above to separate the two cleavage products. Fractions containing the $X b a I$ A fragment were pooled and dialyzed against TE-PMSF. The fragment was stored on ice until used.

\section{Isolation of Ad5/Ad12 Recombinant Vi- ruses}

Human 293 cells were cotransfected with the DNA-protein complex of the $X b a I A$ fragment of Ad5 mutant dl 309 and EcoRI- linearized plasmid p5125E $1 \mathrm{~b}$ by use of the method described by Van der Eb and Graham (1980). In a typical transfection assay, $1 \mu \mathrm{g}$ of sucrose gradient purified $X b a I A$ fragment (DNA-protein complex) was cotransfected with $5 \mu \mathrm{g}$ of plasmid onto a 5 $\mathrm{cm}$ dish of 293 cells. Four hours after transfection the medium was removed, the cells were washed twice with PBS and were overlayed with $8 \mathrm{ml}$ of $\mathrm{MEM}+2 \%$ fetal calf serum containing $0.7 \%$ agar. After 5 days another $4 \mathrm{ml}$ of overlay medium was added. On Days 8-10 the cells were stained with neutral red and individual plaques were picked.

\section{Virus Minilysate Procedure}

Individual plaques from the cotransfection assay were picked. Freeze-thawed twice in PBS $+2 \%$ fetal calf serum and were subsequently used to infect $5-\mathrm{cm}$ dishes of 293 cells. After the development of cytopathogenic effect (3-4 days post infection) cells were scraped off, centrifuged, and resuspended in $0.5 \mathrm{ml}$ of $0.01 M$ TrisHCL buffer, pH 8.2. After two cycles of freeze-thawing, cell debris was removed by centrifugation ( $5 \mathrm{~min}$ at $3000 \mathrm{rpm}$ ) and the supernatant was extracted with an equal volume of genentron. After centrifugation, the supernatant was removed and incubated with $100 \mu \mathrm{g} / \mathrm{ml}$ of Pronase in the presence of $0.5 \%$ SDS for $30 \mathrm{~min}$ at $37^{\circ}$. The mixture was then extracted with phenol and precipitated with ethanol. On the average, $1 \mu \mathrm{g}$ of viral DNA could be isolated in this way.

Procedures for $\left[{ }^{35} \mathrm{~S}\right] \mathrm{methionine,} \mathrm{cell} \mathrm{la-}$ beling, immunoprecipitation, and $\mathrm{S} 1 \mathrm{nu}-$ clease analysis have been previously described (Bernards et al, 1982).

\section{RESULTS}

The strategy followed to construct the Ad5/Ad12 recombinant virus was based on the procedure described by Stow (Stow, 1981). First a hybrid early region 1 plasmid containing the E1a region of Ad5 and the E1b region of Ad12 was constructed. This plasmid was then cotransfected with a subgenomic fragment of the Ad5 mutant 
dl 309 (Jones and Shenk, 1979) to 293 cells, a human embryonic kidney line expressing the E1 region of Ad5 (Graham et al, 1977). In theory, virus plaques can only be formed if recombination has occurred between the hybrid E1 plasmid and the subgenomic Ad5 DNA fragment. To obtain a viable recombinant virus the hybrid $\mathbf{E} 1$ plasmid has to meet three requirements. First, it must have an intact or nearly intact Ad5 leftterminal repeat for proper replication of the virus (Stow, 1982). Second, to ensure proper insertion of the hybrid $\mathrm{E} 1$ region in the recombinant viral genome, the hybrid plasmid should contain Ad5 sequences derived from the region directly flanking the E1 region to allow homologous recombination to occur between the hybrid E1 region and the subgenomic Ad5 DNA fragment. Third, the hybrid $E 1$ region has a size limit: the length of the recombinant viral genome should not exceed $105 \%$ of the wild-type genome to allow proper packaging ( $\mathrm{K}$. Berkner, personal communication).

Figure 1 shows the exact structure of the Ad5/Ad12 hybrid plasmid and of the subgenomic Ad5 dl 309 DNA fragment. The plasmid p5125E1b was constructed from an existing Ad5/Ad12 hybrid plasmid pAd512 (Bernards et al, 1982), by use of standard cloning procedures described elsewhere (Bos et al., 1981; Bernards et al., 1982). The plasmid pAd5125E1b contains the Ad5 E1a sequences from nt 79 to 1574 (HpaI site). This Ad5 E1a segment was joined via a BamHI linker to the Ad12 E1b fragment, extending from nt 1344 (MboI site) to nt 3950 ( $R$ saI site) of the Ad12 sequence. The Ad12 E1b segment was joined via another $B a m H I$ linker at the $R$ saI site at nt 3950 to a $B g l$ II fragment of Ad5 (nt 3328-8892). The viral sequences were inserted into the plasmid vector pAT153 (Twigg and Sherratt, 1980). Although the left terminal $78 \mathrm{bp}$ were missing from the Ad5 inverted terminal repeat present in the plasmid, it was to be expected that this defect would be repaired in vivo after recombination and replication (Stow, 1982). The subgenomic Ad5 DNA fragment used in the cotransfection was the $X b a I$ A fragment of the Ad5 mutant dl 309 (3.8-100\%). To increase the yield of recombinants we used sucrose gradient-purified $X b a I$ A fragment with the terminal protein covalently linked to the right end of the DNA fragment.

To obtain an intact hybrid viral genome, the hybrid plasmid was linearized with EcoRI and cotransfected with the dl 309 $X b a I$ A-fragment onto confluent cultures
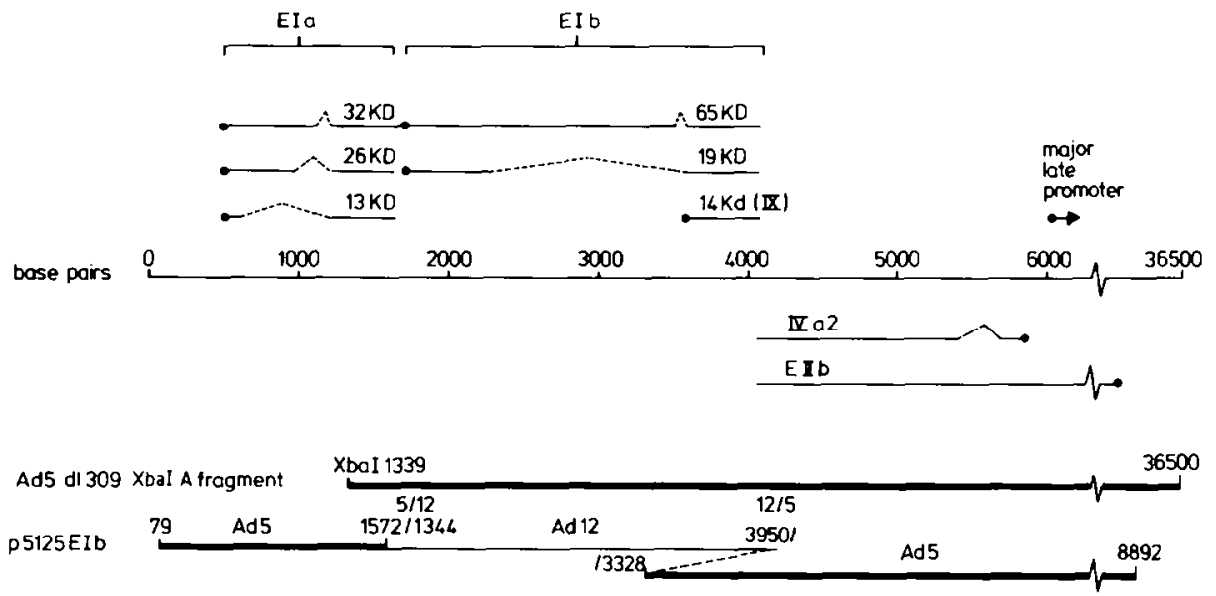

Fir. 1. Schematic representation of the Ad5/Ad12 hybrid plasmid used for recombination with the Ad5 dl $309 \mathrm{XbaI}$ A-fragment. Top: positions of the major RNAs transeribed from region Ela and $\mathrm{E} 1 \mathrm{~b}$ of the adenovirus genome. Dotted lines represent intervening sequences. Bottom: structure of the Ad5 dl $309 \mathrm{XhaI} A$-fragment and of the plasmid p5125F1b. Thick lines represent Ad5-derived sequences, thin lines Ad12-derived sequences. 
of human 293 cells by means of the calcium phosphate technique (Van der $\mathrm{Eb}$ and Graham, 1980). Four hours after transfection the medium was removed from the cells and replaced by an agar overlay. The first plaques became visible 5 days after transfection with a maximum plaque count after 9 days. Plaque formation occurred only when the hybrid plasmid was cotransfected with the dl $309 \mathrm{XbaI}$ A fragment. To screen for recombinants, individual plaques from the cotransfection assay were picked and viral DNA prepared from virus minilysates were analyzed by restriction endonuclease digestion (see Materials and Methods). Ad5/Ad12 recombinants were plaque-purified two more times on 293 cells and subsequently grown in large scale on HeLa cells. Viral DNA was isolated and subjected to digestion with restriction endonuclease Sall. The Ad5 mutant dl 309 has four SalI sites (Fig. 2). If the dl $309 \mathrm{XbaI}$ A fragment has recombined with the hybrid E1 plasmid, the resulting hybrid virus should have an additional Sall site, located in the Ad12 E1b region. This would result in two novel Sall fragments and 11 and 15 map units, respectively. Two of the six plaques screened Rc613 and Re621, showed the SalI digestion. pattern expected for a recombinant virus. Additional fine mapping and Southern blotting experiments were all consistent with the structural organization of the recombinant viral genome shown in Fig. 2, i.e., the Ad5/Ad12 hybrid E1 region positioned at the extreme left end of the recombinant viral genome (not shown). No
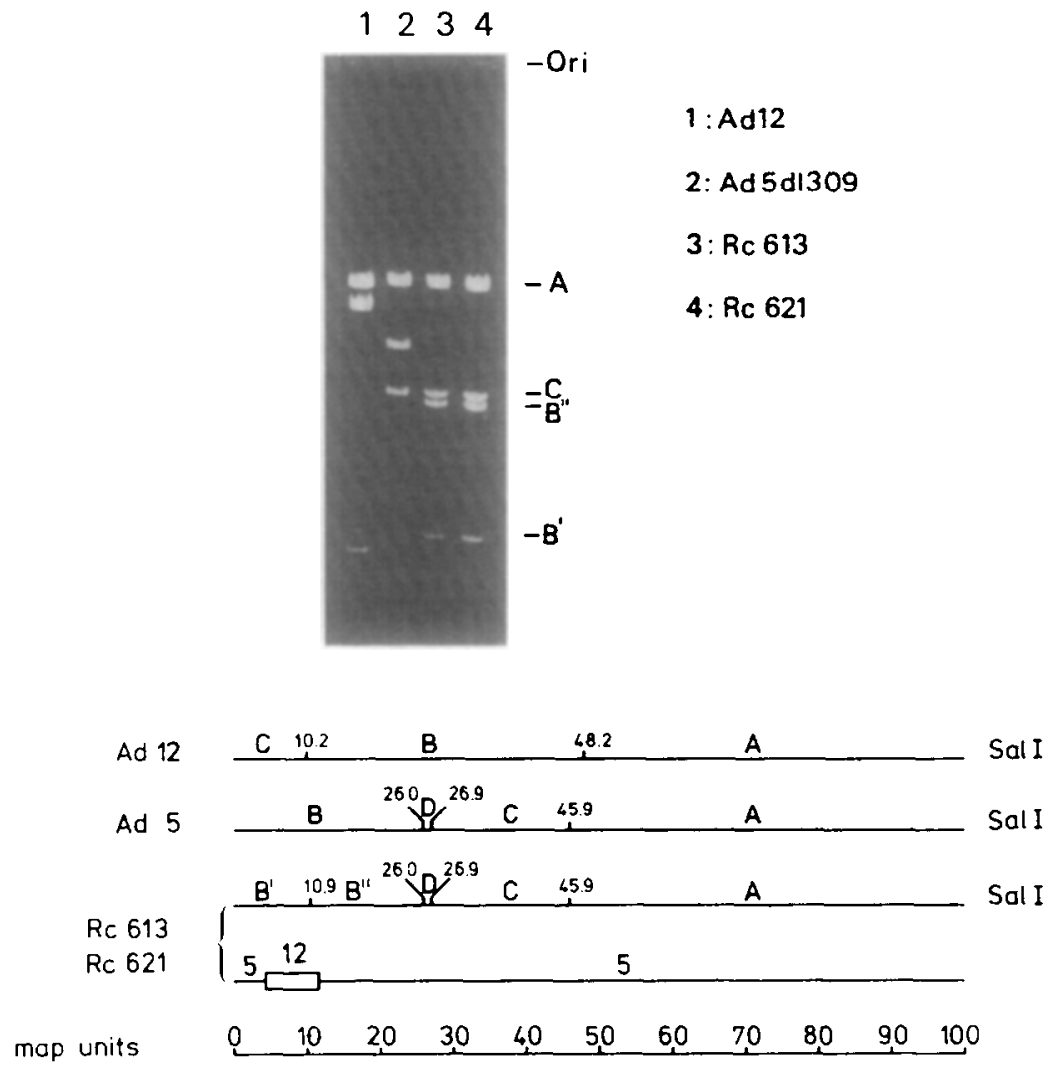

Fir. 2. Agarose gel electrophoresis of Sall digests of the recombinant viruses. Top: $0.5 \mu \mathrm{g}$ of Ad12 DNA (lane 1), Ad5 dl 309 DNA (lane 2), Re613 DNA (lane 3), or Rc621 (lane 4) was digested to completion with restriction endonuclease Sall. Fragments were separated on a $0.7 \%$ agarose gel. Rottom: Cleavage maps of Ad12 and Ad5 DNA with SaIT and predicted cleavage map of the recombinant viral genomes Rc613 and Re621. 
differences in restriction pattern have been detected between the recombinants Rc613 and Rc621. Although we cannot exclude minor differences between these two viruses, we infer that they are both the product of a recombination event in the Ad5 segment between nt 3328 and 8892 .

\section{Expression of Early Region 1 Genes of the Recombinant Virus in Infected Cells}

To test expression of the Ad12 E1b region present in the recombinant virus, cultures of human embryonic kidney cells were infected with the recombinants Rc613 and Re621 at a m.o.i. of $100 \mathrm{PFU} /$ cell and labeled 12 to $16 \mathrm{hr}$ postinfection with $\left[{ }^{35}\right.$ S $]$ methionine. Figure 3 shows the autoradiograph of the SDS-polyacrylamide gel used to separate $\mathrm{T}$ antigens precipitated with highly specific Ad5 and Ad12 antitumor sera from the Re613- and Re621infected cells. The autoradiograph shows that the Ad12 E1b region of the recombinant virus directs the synthesis of the two Ad12 E1b tumor antigens of 54 and 19 $\mathrm{kDa}$, respectively. The only Ad5 protein precipitated is a $14-\mathrm{kDa}$ polypeptide, probably derived from early region 4 (Downey et al, 1983). An extract from Ad5-transformed cells was precipitated with the same sera to show that the anti-Ad5 serum indeed recognizes the Ad5 E1b tumor antigens of 58 and $19 \mathrm{kDa}$ (lanes $X h o C$ ).

Additional evidence for the correct expression of the Ad12 E1b region in the recombinant virus was obtained from $\mathrm{S} 1$ nuclease RNA mapping experiments. Total cytoplasmic RNA was isolated from human embryonic kidney cells, $12 \mathrm{hr}$ postinfection with Ad12 or with the recombinant viruses. The Ad12 E1b probe used in the S1 experiment was a 5 -end-labeled $P v u I I$ fragment (nt 1901 to 3617 ). This probe will detect the transcript of the gene for the structural protein IX and the common splice-acceptor site of the two Ad12 E1b mRNAs of $1 \mathrm{~kb}$ and $2.2 \mathrm{~kb}$, respectively (Fig. 4). RNAs from cells infected with either Ad12 or the recombinant virus both protect the expected segments of $267 \mathrm{nt}$ and $249 \mathrm{nt}$ of the DNA probe against S1 digestion. These data show that the Ad12

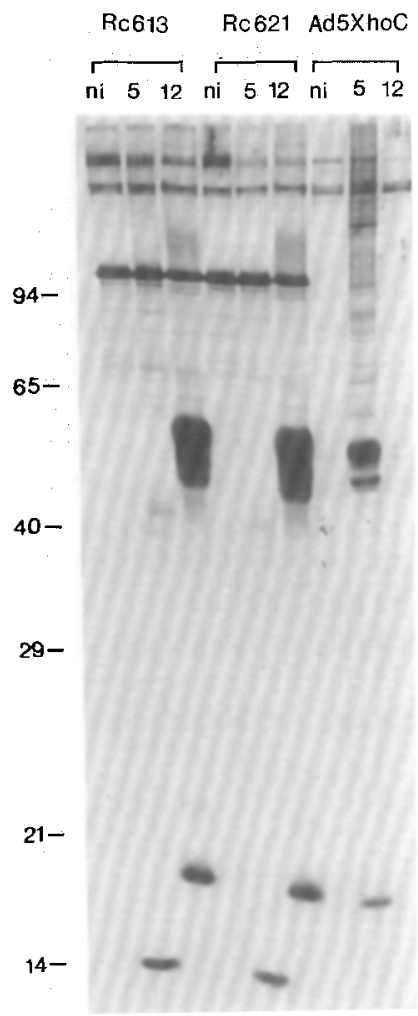

FIG. 3. Polyacrylamide gel electrophoresis of T antigens precipitated from cells lytically infected with recombinant virus. Human embryonic kidney cells were infected with the Ad5E1a/Ad12E1b recombinant viruses Rc613 and Rc621 at a multiplicity of infection of $100 \mathrm{PFU} /$ cell and labeled 12-16 hr postinfection with $\left[{ }^{85}\right.$ S]methionine. Labeled extracts were precipitated with preimmuneserum (lanes ni), Ad5 anti-T serum (lanes 5) and Ad12 anti-T serum (lanes 12). The same sera were used to precipitate $T$ antigens from labeled baby rat kidney cells transformed with the Ad5 XhoI C fragment $(0-15 \%$, lanes $X h o C)$. The position of the molecular weight markers are indicated.

gene for the structural protein pIX is expressed in cells infected with the recombinant virus.

Likewise, S1 mapping was used to check expression of Ad5 E1a in cells infected with the recombinant virus. The probe used in this experiment was a 488-bp 3 '-labeled NarI fragment derived from the Ad5 E1a region (nt 814 to 1302). The $12 \mathrm{~S}$ E1a mRNA can protect a segment of 160 nucleotides of this probe against $\mathrm{S} 1$ digestion, while the $13 \mathrm{~S}$ mRNA can protect a segment of 


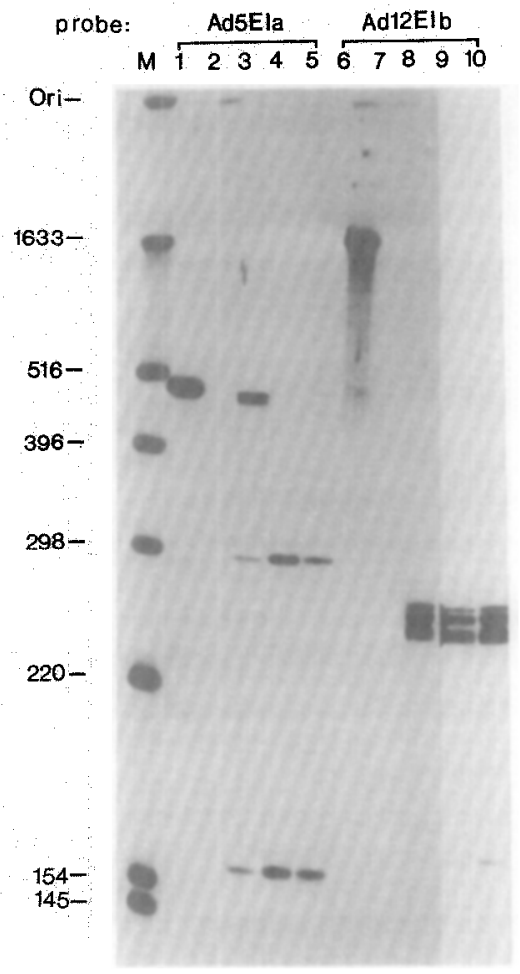

FIG. 4. S1 nuclease analysis of RNAs from the regions E1a and E1b in lytically infected cells. Total cytoplasmic RNA was isolated from human embryonic kidney cells $12 \mathrm{hr}$ after infection (m.o.i. $100 \mathrm{PFU} /$ cell) with Ad5 dl 309, Ad12 or the recombinant viruses Re613 and Re621. The Ad5 Ela probe was a ${ }^{52} \mathbf{P}-3^{\prime}-$ end-labeled NarI fragment (nt 814-1302). The Ad12 E1b probe was 1716-bp 5'-end-labeled PruII fragment (nt 1901-3617). Twenty micrograms of RNA from infected cells was hybridized to the DNA probe and digested with S1 nuclease. Protected segments were separated on a $5 \%$ polyacrylamide $7 M$ urea gel. Lane 1, The untreated Ad5 E1a probe; lane 2, the Ad5 E1a probe hybridized to tRNA; lanes 3,4 , and 5, the Ad5 E1a probe hybridized to Ad5 dl 309 lytic RNA, Re613 lytic RNA, and Rc621 lytic RNA, respectively; lane 6. the untreated Ad12 E1b probe; lanes 7, 8, 9, and 10, the Ad12 E1b probe hybridized to tRNA, Ad12 lytic RNA, Rc613 lytic RNA, and Re621 lytic RNA respectively. For lanes 9 and 10 a fourfold shorter exposure is shown to resolve the two neighboring protected segments.

$298 \mathrm{nt}$ of the same probe. Figure 4 shows that both with Ad5 dl 309 lytic RNA and with RNA from cells infected with the recombinant virus, segments of 160 and 298 nt can be protected. This shows that the
Ad5 $\mathrm{F} 1$ a region in the recombinant virus is also faithfully expressed.

\section{The Ad5/Ad12 Recombinant Virus Does Not Show a Host Range Phenotype}

The Ad5 mutant dl 309 has lost three of the four $X b a I$ cleavage sites. At least one of these sites was lost due to a deletion of viral sequences between 83 and 85 map units (Jones and Shenk, 1979). Nevertheless, this virus is viable in normal human cells. To test whether the recombinant virus has an altered host range compared to the dl 309 mutant, one of the recombinants, Re613, was grown on 293 cells and serial dilutions of the virus stock obtained were plated onto replicate dishes of HeLa cells, 293 cells and human embryonic kidney cells in a plaque assay. Ad5 dl 309 and Ad12 virus stocks were also added to the experiment for comparison.

The results of the plaque assay, presented in Table 1, show that the plaquing efficiency of the recombinant virus is in the same order of magnitude on human embryonic kidney cells as on 293 cells. Like Ad12, the recombinant virus does not form plaques on HeLa cells. However, the hybrid virus could be grown to high titers in HeLa cells. We therefore conclude that the failure of the recombinant virus to form plaques on HeLa cells is not due to its inability to replicate in these cells, but rather, like Ad12, to a poor capacity of the virus to lyse infected HeLa cells.

\section{Oncogenicity of the Recombinant Virus in Newhorn Hamsters}

To test the oncogenic potential of the recombinant virus in newborn hamsters

TABLE 1

Host Range Phenotype of the RECOMBINANT VIRUS

\begin{tabular}{lrrc} 
& \multicolumn{3}{c}{ Titer (PFU) } \\
\cline { 2 - 4 } \multicolumn{1}{c}{ Virus } & 293 cells & HEK cells & HeLa cells \\
\hline Ad5 d1309 & $1 \cdot 10^{9}$ & $6 \cdot 10^{8}$ & $8.5 \cdot 10^{8}$ \\
Ad12 & $\begin{array}{r}3.2 \cdot 10^{7} \\
\text { Re613 }\end{array}$ & $\begin{array}{r}8.4 \cdot 10^{7} \\
9 \cdot 10^{9}\end{array}$ & - \\
\hline
\end{tabular}


$10^{8} \mathrm{PFU}$ of recombinant virus were injected subcutaneously into 24 -hr-old Syrian hamsters. Whereas all of the control animals injected with Ad12 developed tumors within 2 months, none of the animals injected with Rc613 or Rc621 have developed tumors up to 9 months postinjection (Table 2 ). These results show that the modulation of the oncogenic potential of adenoviruses is brought about by either other or additional genes than those encoded by the early region $1 \mathrm{~b}$.

\section{DISCUSSION}

We have constructed an Ad5/Ad12 recombinant virus in which the $E 1 b$ region of the nononcogenic Ad5 is replaced by the homologous transcriptional unit of Ad12. We show that in human embryonic kidney cells, lytically infected with the recombinant virus, there is expression of the Ad5 E1a and Ad12 E1b genes.

It is difficult to estimate the level of expression of the Ad12 E1b region in the recombinant virus as compared to the expression of the E1b region in wild type Ad12. The reason for this is that the onset of expression of E1b in wild-type Ad12 lytic infection is later when compared to Ad5 or the recombinant virus. It has been shown that Ad5 mutants with a defect in E1b show a 4 logs decreased plaquing efficiency on HEK cells as compared to 293 cells (Jones and Shenk, 1979). The best evidence that the $\mathrm{E} 1 \mathrm{~b}$ region in the recombinant virus is expressed at normal or next to normal, levels, is therefore provided by the finding that the recombinant virus replicates nearly as efficiently on HEK cells as on 293 cells (Table 1 ).

No plaques could be scored with the recombinant on HeLa cells, however, the virus does replicate efficiently on these cells since high virus yields could be harvested from infected HeLa cultures. These results show that the Ad12 E1b region can fully replace the Ad5 E1b region in lytic infection. These results are in good agreement with those of others (Brusca and Chinnadurai, 1981; Williams et al., 1981; Rowe and Graham, 1981) who found that Ad2 and Ad5 E1b host range mutants could be
TABLE 2

TLMORIGENICITY OF THE RECOMBINANT VIRUS IN NEWBORN HAMSTERS

\begin{tabular}{lccc}
\hline Virus & $\begin{array}{c}\text { No. of } \\
\text { animals } \\
\text { injected }\end{array}$ & $\begin{array}{c}\text { No. of } \\
\text { animals } \\
\text { with } \\
\text { tumors }\end{array}$ & $\begin{array}{c}\text { Latent period } \\
\text { (days) }\end{array}$ \\
\hline Ad12 & 10 & 9 & 30 -50 \\
Ad5 d1309 & 10 & 0 & - \\
Re613 & 12 & 0 & - \\
Re621 & 10 & 0 & - \\
\hline
\end{tabular}

complemented by coinfection with wildtype Ad12. However, our results are conflicting with those of Shiroki et al. (1982) who concluded that Ad12 E1b does not complement Ad5 E1b.

Our present results also show that complementation between Ad5 and Ad12 is not restricted to the early region 1 gene block. This was demonstrated by the finding that the Ad12 gene for the intermediate early structural protein pIX was expressed in cells infected by the recombinant virus. Since the gene for protein IX is not expressed in cells transformed with Ad5 or Ad12 early region 1 plasmids, we conclude that some Ad5 gene products, located outside the $\mathbf{E} 1$ region, is capable of activating the Ad12 protein IX promoter in the recombinant virus.

Our interest in constructing the Ad5E1a/Ad12E1b recombinant virus was aroused by the difference in oncogenicity between Ad5 and Ad12. As mentioned earlier we have previously used an Ad5 E1a/Ad12 E1b plasmid in transformation studies with primary rat kidney cells. Cells transformed with this hybrid plasmid were highly oncogenic when injected into nude mice (Bernards et al, 1982). However, in the present study we find that if essentially the same plasmid is introduced into an intact virus genome of nononcogenic Ad5, this does not lead to a recombinant virus with oncogenic potential in newborn hamsters. This finding implies that gene product(s) other than the Ad12 E1b region are required to make a virus oncogenic. At this stage, it is difficult to predict which gene products or 
additional gene product(s) are involved in viral oncogenicity.

One possibility is that the identity of the Ela region is important in determining the oncogenic potential of a virus. We have recently found evidence for this hypothesis by showing that adenovirus-transformed rat cells expressing the Ad12 E1a region can escape the thymus-mediated immune surveillance of the syngeneic host, while cells expressing the Ad5 E1a region can not (Bernards et al, 1983b). Another possibility is that early region 3 gene products are involved in the process of tumor induction by the virus. This region is partially deleted in our recombinant virus since we have used the adenovirus type 5 mutant dl 309, which carries a lesion in the $\mathrm{E} 3$ region, for recombinantion with the hybrid plasmid. It has recently been shown that one of the glycoproteins specified by this region is closely associated with the class I major histocompatibility complex antigens (Signäs et al., 1982). It is conceivable that this protein plays a role in modulating the $\mathrm{T}$ killer cell response against tumor cells.

We have recently isolated an Ad5 recombinant virus which carries both region E1a and region E1b of Ad12. This virus also contains an intact E3 region. Analysis of the oncogenic potential of this virus should shed more light on the role of additional gene products in the process of tumor induction by adenoviruses.

\section{ACKNOWLEDGMENTS}

We thank Dr. T. Shenk for the gift of the Ad5 mutant dl 309, Dr. J. L. Bos for discussion and Ms M. A. Veeren-Vink for typing the manuscript.

This work was supported in part by the Netherlands Organization for the Advancement of Pure Research (ZWO), through the Foundation for Fundamental Medical Research (FUNGO).

\section{REFERENCES}

Bernards, R., Houwelling, A. Schrier, P. I., Bos, J. L., and VAN DER EB, A. J. (1982). Characterization of cells transformed by Ad5/Ad12 hybrid early region 1 plasmids. Virology 120, 422-432.

Bernarins, R., Schrier, P. I., Bus, J. L., and VAN DER EB, A. I. (1983a). Role of adenovirus types 5 and
12 early region $1 \mathrm{~b}$ tumor antigens in oncogenic transformation. Virology 127, 45-54.

Bernards, R., Schrier, P. I., Houweling, A., Bos, J. L., VAN Der EB, A. J., ZiJ.stra, M., and Mei.IEF, C. J. M. (1983b). Cells transformed by adenovirus type 12 cause tumors by evasion of $\mathrm{T}$-cell immunity. Nature, in press.

Bos, J. L., Polder, L. J., Bernards, R., Schrier, P. I., VAN DEN ElSEN, P. J., VAN DER EB, A. J., and VAN ORMONIT, H. (1981). The $2.2 \mathrm{~kb}$ F1h mRNA of human Ad12 and Ad5 codes for two tumor antigens starting at different AUG triplets. Cell 27, 1.21-131.

Brusca, J. S., and Chinnadurai, G. (1981). Transforming genes among three different oncogenic subgroups of human adenoviruses have similar replicative functions. J. Virol 39, 300-305.

Downey, J. F., Rowe, D. T., BaCchetTi, S., Graham, F. L., and BAYLEY, S. T. (1983). Mapping of a 14.000 dalton antigen to early region 4 of the human adenovirus 5 genome. $J$. Virol 45, 514-523.

Flint, S. J. (1980). Transformation by adenoviruses. In "Molecular Biology of Tumor Viruses II: DNA Tumor Viruses" (J. Tooze, ed.), 2nd ed., pp. 547576. Cold Spring Harbor Laboratories, Cold Spring Harbor, New York.

Freeman, A. E., Black, P. H., Wolford, R., and HUEBNER R. J. (1967). Adenovirus 12 rat-embryo transformation system. J. Virol 1, 362-367.

GRAham, F. L., VAN DER EB, A. J., and HeYNEKeR, H. L. (1974). Size and location of the transforming region in human adenovirus type 5 DNA. Nature (Londom) 251, 687-691.

Graham, F. L., Smiley, J., Russell, W. C., and NaIkN, R. (1977). Characteristies of a human cell line transformed by DNA from human adenovirus type 5. J. Gen. Virol 36, 59-72.

HARWOOD, L. M. J., and GALLIMORE, P. H. (1975). A study of the oncogenicity of adenovirus type 2 transformed rat embryo cells. Int. J. Cancer 16 , 498-508.

JoNes, N., and SHENK, T. (1979). Isolation of adenovirus type 5 host range deletion mutants defective for transformation of rat embryo cells. Cell 17,683689.

MAK, S., MaK, I., Smiley, J. R., and Graham, F. I. (1979). Tumorigenicity and viral gene expression in rat cells transformed by Ad12 virions or by the EcoRI C fragment of Ad12 DNA. Virology 98, 456460.

MCAllister, R. M., Nicholson, M. O., Lewis, A. M., MacPherson, I., and Huebner, J. R. (1969). Transformation of rat embryo cells by adenovirus type 1. J. Gen. Virol 4, 29-36.

Rowe, D. T., and Graham, F. L. (1981). Complementation of adenovirus type 5 host range mutants by Ad12 in co-infected HeLa and BHK-21 cells. $\boldsymbol{j}$. Virol 38, 191-197. 
Shiroki, K., Hanma, H., Shimojo, H., Yano, S., OJma, S., and FujInaGA, K. (1977). Establishment and characterization of rat cell lines transformed by restriction endonuclease fragments of adenovirus 12 DNA. Virology 82, 462-471.

Shiroki, K., Maruyama, K., Saito, I., Fukui, Y., YaZAKI, K., and SHimojo, II. (1982). Dependence of tumor forming capacities of cells transformed by recombinants between adenovirus types 5 and 12 on expression of tarly region 1. J. Virol. 42, 708718.

Signäs, C., Katze, M. G., Persson, H., and PhIllipson, L. (1982). An adenovirus glycoprotein binds heavy chains of class I transplantation antigens from man and mouse. Nature (London) 299, 175-178.

STow, N. D. (1981). Cloning of a DNA fragment from the left-hand terminus of the adenovirus type 2 genome and its use in site-directed mutagenesis. $J$. Virol. 37, 171-180.
Stow, N. D. (1982). Infectivity of adenovirus genomes lacking DNA sequences from their left-hand termini. Nucleic Acids Res. 10, 5105-5119.

Twigg, A. J., and SherratT, D. (1980). Trans-complementable copy-number mutants of plasmid $\mathrm{Col}$ E1. Nature (Lomdon) 283, 216-218.

Van der Eb, A. J., and Graham, F. L. (1980). Assay of transforming activity of tumor virus DNA. In "Methods in Enzymology" (L. Grossman and K. Moldave. Eds.), Vol. 65, pp. 826-839. Academic Press, New York.

Van den Elsen, P. J., De Pater, S., Houweling, A., VAN DER VFER, J., and VAN DER EB, A. J. (1982). The relationship between region E1a and $E 1 b$ of human adenoviruses in cell transformation. Gene $18,175-185$.

WrLlaMS, J., Ho, S. Y., and GALOS, R. (1981). Evidence for functional relatedness of products encoded by the transforming sequences of human adenovirus types 5 and 12. Virology 110, 208-212. 